\title{
GRANDES TERRITORIALIDADES, PLANEJAMENTO E QUESTÕES AMBIENTAIS NO BRASIL
}

Ralfo Matos

Os espaços territoriais traduzem poderes notáveis, carregados de atributos físicos e ambientais, sob os quais se desenvolvem conflitos e processos de transformação que dão sentido geográfico e econômico a história social da ocupação humana. Representam desafios a gestão governamental, especialmente se pensada de forma integrada e participativa.

A omissão do espaço nos diagnósticos e programas de desenvolvimento foi recorrente em muitos dos planos governamentais levados a cabo durante o século XX. Esta prática - que priorizava os investimentos setoriais e negligenciava o espaço enquanto categoria de análise essencial - foi evidente e lamentável.

A análise fundada na espacialidade possui a singular capacidade de dar visibilidade única, em termos metodológicos, à realidade social. Isto porque integra setores e atividades, conjuga expressões políticas e socioculturais; explicita conflitos em áreas centrais e periféricas; aponta zonas de insegurança social e de risco ambiental; enfim, exibe diversos tipos de impactos sócio-ambientais que, no longo prazo, podem comprometer qualquer esforço de desenvolvimento sustentável.

\section{1 - ESPAÇOS TERRITORIAIS: FRONTEIRAS EM MOVIMENTO E DIVISÕES REGIONAIS}

Os espaços territoriais no Brasil são, antes de tudo, heranças dos tempos da colonização, Império e primórdios da República. Cristalizações de poder e jurisdição, por onde a idéia de unidade nacional ficou garantida, através do que se pode chamar de pacto federativo. Uma espécie de grande acordo apoiado em bases territoriais, a partir das quais as elites políticas, as oligarquias e setores econômicos diversos se reorganizaram, em busca de formas de controle de conflitos em potencial e de reacomodação de seus interesses gerais e/ou específicos.

A proclamação da República em 1889, por exemplo, surgiu não só como resposta ao decreto imperial que pôs fim a escravidão no ano anterior, mas também como reação ao centralismo típico do Império. A adoção do federalismo soava como ruptura baseada em Cadernos do Leste

Artigos Cientificos

Belo Horizonte, Edição Especial, 2000 a 2008 
um novo arranjo institucional. Contudo, o modelo federativo que se pretendia descentralizador, só o foi episodicamente na história republicana.

$\mathrm{Na}$ verdade, a República sempre foi centralizadora, embora tenha assistido, durante décadas, expressões descentralizadas de mandonismo político-econômico de tipo local e regional (como nas diversas expressões de coronelismo e cangaço da primeira metade do século $\mathrm{XX}$ ), verdadeiros poderes paralelos claramente territorializados, presentes, em alguma medida, até os dias de hoje. A dimensão do país e a precariedade de instrumentos disponíveis para gerenciar a jovem e complicada nação, ainda marcada por manifestações de dissoluções, pode ter inspirado o "modus operandis" que os militares adotaram para fazer valer o projeto de república que o epíteto “ordem e progresso" procurava determinar.

De toda forma, a duração mais ou menos longa de determinadas divisões territoriais gera tradições socioculturais e econômicas, elites reconhecidas nacionalmente e poder econômico fortemente estabelecido. A idéia de Estado unitário certamente persiste em nosso imaginário, como uma espécie de "conquista territorial" que tipifica parte da história do Ocidente Capitalista dos séculos XVIII, XIX e XX, quando a constituição dos estados nacionais se fazia em meio a disputas territoriais que varreram extensas áreas da Europa e Ásia.

Terra, pátria, solo-mãe, liberdade, justiça, "guerra-justa”, povo heróico e guerreiro são imagens recorrentes nos hinos nacionais que cultuam, não raro, a fé no destino de potência emergente. O Brasil, grande nação tropical ao sul do equador com unidade lingüística e sem conflitos religiosos, não foge ao pressuposto da coesão social fundada em algum tipo de pacto que focalize a nacionalidade. Mesmo que a custa de violentas lutas fratricidas que marcaram tantos movimentos separatistas e/ou regionalistas do século XIX. Mesmo que tenhamos que reconhecer a estratégia colonial portuguesa exitosa, capaz de expandir e manter a integridade territorial do Brasil entre a Colônia e o Império. (CASTRO, 1997).

\section{2- IMPORTÂNCIA HISTÓRICA DAS FRONTEIRAS TERRITORIAIS}

Divisões territoriais, como as estaduais, têm sua origem associada a fatores de natureza política e econômica.

É bem verdade que as fronteiras de algumas das atuais Unidades da Federação guardam ainda semelhanças com o formato de determinadas capitanias hereditárias do tempo do Brasil Colônia. A durabilidade de algumas dessas fronteiras se explica pela força 
de séculos de poder colonial e pela acomodação do conjunto de interesses das elites econômicas e políticas no interior dos espaços das capitanias e, mais tarde, das províncias, já na época do Brasil Império.

Contudo, é provável que tais fronteiras tenham se tornado tão "permanentes" em face das formas de resolução dos vários conflitos provinciais do século XIX, das conciliações político-administrativas sob o comando do governo imperial, e mesmo depois, na república, sob a contraditória convivência entre centralismo e regionalismo até 1930.

A Revolução de 1930 tornou-se, de fato, um divisor de águas na história do país, porque ao interromper os arranjos políticos das elites de São Paulo e Minas na República Velha, introduziu grandes mudanças a partir daí, renovando, por assim dizer, o pacto federativo. O desaparecimento dos ganhos auferidos pelas velhas elites estaduais decorrentes das tarifas impostas às mercadorias quando circulavam pelas fronteiras territoriais foi, sem dúvida, um estímulo decisivo para a constituição e unificação do mercado interno brasileiro e expansão do transporte rodoviário, nos anos subseqüentes. ${ }^{1}$

O Rio Grande do Sul, palco de históricas manifestações separatistas, estabelece-se politicamente no centro da federação, com Getúlio Vargas. A intensa reestruturação rapidamente difunde-se nos níveis econômico, social e territorial ao longo dos anos de 1930. A indústria afirma-se apoiada na expansão das cidades sudestinas e nos programas de substituição de importação. Um pacto social se impõe. O operariado nascente é contemplado com a instituição das leis trabalhistas do Estado Novo e com a introdução do salário mínimo. O jovem empresariado da indústria passa a ser protegido política e economicamente, e as oligarquias agrárias permanecem intocadas. Boa parte dessa oligarquia, mesmo conservando fatias expressivas de poder político, se viu debilitada economicamente em decorrência da devastadora crise da cafeicultura no período e pela perda de rendimentos derivados das taxas de transposição das velhas fronteiras territoriais entre os estados. Tais mudanças vieram atingir fortemente o poder das velhas oligarquias regionais, fazendo desobstruir o espaço geográfico para a afirmação do empresariado industrial e para a grande expansão da infraestrutura econômica e dos mercados de trabalho e de consumo nas décadas seguintes.

\footnotetext{
1 Antes disso, grande parte do transporte de longa distância de pessoas, bens e mercadorias entre os estados se fazia, preferentemente, por meio da navegação marítima e fluvial, o que evidentemente representava uma evidente redução de custos, mesmo se comparados com os custos do transporte ferroviário (que vinha se desenvolvendo, a duras penas, desde fins do século XIX a partir do Rio de Janeiro). Essa condição favorecia a expansão territorial entre localidades do vasto litoral brasileiro ou ao longo de grandes rios navegáveis, como no trecho do São Francisco entre Juzeiro e Pirapora (Paulo Afonso foi uma das primeiras quedas dágua do Brasil a desaparecer em favor da geração de hidreletricidade). 
Nesse novo ambiente, no qual mudanças constitucionais se sucedem (1934 e 1946) já se podia pensar em um país forjado por uma perspectiva mais unitária, com integração, normatização e regras voltadas a um futuro industrial. Surgia então a necessidade do planejamento governamental, como uma espécie de imposição e inovação em termos de ação do executivo.

De fato, após a quebra de parte substancial do poder das oligarquias agrárias, seja pela ruína da cafeicultura e a presença impositiva da Ditadura Vargas, seja pelas transformações mundiais que irão crescentemente privilegiar o desenvolvimento urbanoindustrial, o planejamento de corte econômico ganhou presença institucional e passou a desenhar ações voltadas para espaços supra estaduais, como o das Grandes Regiões. O projeto nacional de crescimento econômico não poderia se limitar às fronteiras estaduais. Sua lógica intrínseca sempre foi nacional e expansionista, ter-se-ia que privilegiar o país ou, no máximo, grandes espaços territoriais onde houvesse, de fato, diferenças significativas entre eles. As Grandes Regiões acabaram ganhando visibilidade como recorte subnacional importante nesse novo marco regulatório, por razões físico-geográficas (ou fisiográficas) meio óbvias. Talvez por isso, o Nordeste e o Norte, ao preservar seus tão conhecidos recortes territoriais, nunca tenham deixado de ostentar certa visibilidade nos projetos governamentais do período 1930-1960. O planejamento regional viria se afirmar exatamente nesse período.

\section{3- A PRESENÇA DA GEOGRAFIA NAS DIVISÕES TERRITORIAIS}

A Geografia contribui, há muito tempo, para a discussão e normatização das divisões territoriais no Brasil. Inicialmente enfatizava mais o meio físico, focalizando o relevo, hidrografia, clima e vegetação. Posteriormente passou a adotar abordagens mais dinâmicas que se reportam à cultura e à sociedade. Dessa forma, as divisões do espaço deram origem a metodologias de regionalização que ora privilegiavam a idéia de homogeneidade, ora a de complexidade e heterogeneidade. ${ }^{2}$

De toda maneira, constitui uma prerrogativa claramente discernível em muitos estudos geográficos, o fato de o espaço poder ser expresso concretamente por pontos, linhas e volumes, traduzindo conjuntos de lugares não só caracterizados por latitudes e

\footnotetext{
${ }^{2}$ Durante muito tempo as discussões entre estas concepções foram calorosas e recorrentes, sem contudo chegarem a um consenso. Até hoje a conceituação de região guarda certa imprecisão, maior ou menor conforme o país. Cadernos do Leste Artigos Cientificos 
longitudes, mas também por ambientes urbanos e rurais, agrícolas e industriais, dentro de uma dada estrutura demográfica, econômica e social.

A busca de um gabarito para se dividir o espaço nacional em recortes regionais depende muito dos critérios de planejamento em determinado momento, e de fatores físicos, históricos, entre outros. Esta contingência acabou por fazer avançar a pesquisa e as redefinições neste campo de estudo, estimulando a transdisciplinaridade na medida em que se ampliavam as disparidades regionais. Tornava-se urgente aumentar os efeitos propulsores das áreas mais dinâmicas sobre suas periferias, e isso requeria a cooperação de diferentes áreas do conhecimento. A diversidade da Geografia e seus instrumentos técnicos e analíticos sem dúvida favorecem-na nesse debate. (Ver MATOS, 2003).

A título de ilustração enumera-se a seguir algumas das várias propostas baseadas em grandes divisões regionais até 1956. Pode-se registrar as divisões: do engenheiro André Rebouças, em 1889, com a estratificação do país em 10 subespaços; do geógrafo Elisée Réclus, de 1893, cuja proposta pensava o país em oito regiões; a de 1913, do Professor Delgado de Carvalho com a idéia do Brasil dividido em cinco grandes recortes (proposta que se mostrou realista com o passar do tempo); a de 1927, de Piere Denis, com uma divisão em seis regiões; a de 1937, de Betim Paes Leme, com sete grandes regiões; a de 1939, de Moacir Silva com uma divisão em oito regiões; as do próprio IBGE, em 1940 e 1945, com divisões em cinco e sete regiões, respectivamente; e a do IBGE de 1959, com cinco grandes regiões, que deu origem a regionalização adotada na atualidade. (Ver série de mapas $)^{3}$

\section{4- ASCENSÃO E QUEDA DO PLANEJAMENTO GOVERNAMENTAL}

A partir de 1930, mas, sobretudo nos anos de 1950, com o governo de Juscelino Kubitschek, o Estado assume o industrialismo como forma de superar o atraso e subdesenvolvimento, conceitos cujos significados foram muito discutidos à época.

Mediante políticas setoriais de intervenção, pesados investimentos em infraestrutura e criação de estruturas institucionais de fomento, acreditava-se poder fazer o país avançar rumo ao desenvolvimento em curto espaço de tempo. Algumas das premissas do Governo JK indicavam claramente que a dimensão territorial do país deveria ser enfrentada. O binômio juscelinista "energia e transportes" e a fundação de Brasília em área

\footnotetext{
${ }^{3}$ Ver GUIMARÃES, F. "Divisão regional do Brasil”. In: Revista Brasileira de Geografia, Rio de Janeiro, 1941, n. 37. Cadernos do Leste

Artigos Cientificos

Belo Horizonte, Edição Especial, 2000 a 2008
} 
vazia do Planalto Central, foram marcos de uma visão desenvolvimentista, onde grandes obras de engenharia e a conquista de espaços territoriais mediterrâneos traçariam o futuro brasileiro dentro dos ideais da modernidade.

Para tanto foram criados novos órgãos de governo e formou-se um seleto grupo de técnicos e quadros burocráticos espelhados nos modelos de planejamento econômico regional - geralmente de corte autoritário - originários das experiências dos primeiros planos quinquenais da URSS, e, principalmente, do planejamento governamental no Vale do Tennesee sob o período Roosevelt.

Muitas foram as experiências levadas a cabo entre os anos de 1950 até meados dos anos de $1970^{4}$. Contudo, a exaustão dos recursos financeiros internacionais, o fracasso na implementação de vários planos regionais, a corrupção, a malversação de recursos, e o próprio modelo tecnocrático de planejamento da época são alguns dos fatores que explicam o fim da era de ouro do Planejamento Regional no Brasil.

Com isso interrompeu-se também uma série de reflexões teóricas e conceituais associadas à gestão e planejamento, análises inter-regionais e intersetoriais, políticas de correção de desigualdades e medidas compensatórias, discussões sobre modelos teóricos de desenvolvimento - como os que opunham a vocação ruralista brasileira ao industrialismo urbano, os que priorizavam a indústria de base e geração de grandes externalidades (criando a chamada base exportadora), os que se concentravam nos 'vazamentos' centro-periferia, e os que discutiam o aumento das desigualdades e os problemas de distribuição de renda e riqueza.

Tais experiências e discussões teóricas perderam força e eclipsaram-se entre o fim do "milagre econômico", 1972, até pelo menos as mudanças constitucionais de 1988. Após a promulgação da Constituição, ressurge a reflexão socioespacial, escudada na participação popular, com a afirmação do ambientalismo e a discussão do desenvolvimento sustentável, vis-à-vis, a reformatação das práticas de gestão e planejamento, isso já nos anos de 1990.

\footnotetext{
${ }^{4}$ Desde o Império, como observa COSTA (1988:73), a construção da "unidade nacional" e a "integração nacional" eram aspirações bem concretas das elites brasileiras. No século XX, sobretudo após 1930, o Estado deflagrou uma série de iniciativas muito importantes para a integração do espaço nacional. Na década de 50, as políticas territoriais tornaram-se econômico-territoriais, o que tornou as regiões suportes ou objeto de investimentos estatais, momento em que foram criadas agências de desenvolvimento regional como as do Vale São Francisco, a SUDENE, entre outras. Nos anos 60, com a generalização do planejamento, alguns importantes projetos estratégicos foram implementados no bojo dos PNDs (Planos Nacionais de Desenvolvimento), privilegiando vários programas, como os que se concentravam nas cidades médias, telecomunicações, transporte e eletrificação, colonização, zona franca de Manaus, etc. Era a época em que a concentração de poder nas mãos da União tornava os estados muito dependentes dos repasses de recursos federais. Nas décadas seguintes, alterações importantes impactaram as estruturas territoriais regionais do país, como resultado das mudanças econômicas na produção, circulação e consumo, que fizeram expandir as redes geográficas (infraestrutura em geral e sistemas viários interligados, de comunicações e energia) e as redes institucionais (envolvendo a Saúde, Fazenda, Educação e Planejamento) criadas ou fomentadas pelo Estado. Com isso produziu-se laços de coesão mais ou menos duráveis entre partes do território, mas também forças de fragmentação nas velhas regiões.
}

Cadernos do Leste

Artigos Cientificos

Belo Horizonte, Edição Especial, 2000 a 2008 


\section{5- MUDANÇAS ESTRUTURAIS, AMBIENTE E GESTÃO TERRITORIAL}

Com a crise e reestruturação econômica a partir dos anos de 1980, as novas tecnologias de produção e a onda neoliberal põem em marcha inéditos processos de Globalização, a partir dos quais se dá o enfraquecimento da figura do Estado e o quase desaparecimento do planejamento econômico-territorial. A centralização macroeconômica, as crises financeiras, o endividamento externo, $\mathrm{e}$ as experiências fracassadas de planejamento econômico impõem novos papéis ao Estado. A redemocratização, a Constituição de 1988, somadas às pressões externas lançam cunhas na abordagem territorial a partir da ideia de desenvolvimento sustentável.

É o momento em que a variável ambiental ${ }^{5}$ integra-se aos discursos e políticas públicas. Organismos financeiros mudam radicalmente suas orientações exigindo avaliações ambientais, objetivos e metas mais precisas em termos de impactos. O país responde com várias medidas legais, a exemplo da criação do CONAMA em 1986, do Programa Nossa Floresta em 1988, do IBAMA em 1989, do Programa Nacional do Meio Ambiente (PNMA) entre 1990/91, etc. A problemática ambiental começa a redesenhar a questão territorial.

De outra parte, com o recuo do Estado, avançavam as práticas de desregulamentação, em um mundo sem referências legíveis diante das novas temáticas em debate, mesmo que a meta fosse a preservação do meio ambiente. Uma grande inovação surge com a proliferação das Organizações Não Governamentais (ONGs), como contraponto à própria omissão do Estado na gestão territorial. Algumas delas vieram, inclusive, a exercer formas de controle da aplicação de diversos programas de alcance ambiental. Nesse contexto, um novo tripé de parceria ganha e gestão ganha espaço: órgãos transnacionais doadores, ONGs (várias delas apoiadas financeiramente com recursos externos) e governo federal. Gradativamente as Unidades de Conservação ${ }^{6}$ tornam-se o instrumento mais eficaz de proteção à natureza e multiplicam-se pelo país afora. Simultaneamente, proliferam-se as ONGs independentes do Estado (mais de 2000 já registradas), diversificadas tematicamente, acenando para novos significados e

\footnotetext{
${ }^{5}$ Quando se focalizam os recursos naturais, a preservação do patrimônio natural e cultural e as práticas sociais voltadas à participação e formação de cidadania.

${ }^{6} \mathrm{~A}$ importância das regiões selvagens e de se isolar áreas naturais para resguardá-las das intervenções humanas é a primeira noção de unidade de conservação. No Brasil, as reservas naturais receberam o nome de Unidades de Conservação e constituem áreas sob regime especial de administração, destinadas a ordenar o processo de ocupação em espaços dotados de aspectos naturais relevantes (Camargos e Matos, 2000).

Cadernos do Leste

Artigos Cientificos

Belo Horizonte, Edição Especial, 2000 a 2008
} 
possibilidades em termos de regulação. Essas tendências associar-se-iam a um desenvolvimento ecologicamente sustentável, mais democrático e flexível? Ou seriam mais um incentivo à fragmentação político-territorial? (BECKER, 1997).

\section{6- TRANSESCALARIDADE E DESAFIOS À GESTÃO E GOVERNABILIDADE}

No Brasil várias outras discussões passaram a se incorporar à reflexão sobre planejamento e espaço, especialmente quando se torna quase imperiosa a formação e defesa de grandes blocos econômicos supranacionais. As clivagens territoriais perpassam novamente a questão nacional, sobre outras perspectivas.

Refletindo sobre o eixo São Paulo-Buenos Aires e a gestão territorializada, MULLER (1998) observa que, ao nível de governos subnacionais, essa forma de gestão foi duramente atingida pela reforma do Estado, o que resultou em menor volume de obras e investimentos públicos, em cortes de gastos estaduais e corte de subsídios regionais. O estado de São Paulo, graças ao parque industrial instalado, sempre mais independente de repasses federais, sentiu menos o impacto. Lembrando Boisier (1994), o autor adverte que o contexto latino americano dos anos de 1990 é muito distinto do passado, porque marcado pela democratização e aspirações de gestão do desenvolvimento regional, inclusive porque a Globalização criou novas formas de organização territorial. Considerando até o próprio enfraquecimento dos Estados nacionais, conviria pensar em novas formas de gestão oriundas da descentralização produtiva que a economia mundial promove e referir-se a novos arranjos regionais sintonizados com a idéia de sustentabilidade ambiental e econômica. Desenvolvimento sustentável, diante dessa perspectiva, poderia ser definido levando-se em conta a competitividade - o que envolve inovações, financiamento e negociação; a equidade - o que requer participação social, democracia e direitos humanos; e a ecologia - o que impõe limites no uso do meio ambiente.

De toda a forma, ações de desenvolvimento nos dias de hoje pressupõe uma atuação estratégica dos governos na promoção das articulações entre fontes de financiamento, setores com capacidade de gerar inovações e desenhos institucionais dispostos para a negociação. O desenvolvimento sustentável não foge a essa regra, pelo contrário, a reforça. Hoje, governar não depende apenas de um plano ou projeto, desses tão difundidos nas campanhas políticas. Depende de duas dimensões chaves: governabilidade e capacidade de governar. Há que se compatibilizar capacidade de governo Cadernos do Leste

Artigos Cientificos

Belo Horizonte, Edição Especial, 2000 a 2008 
(capital intelectual, organizativo e técnico das equipes) e projeto de governo (conteúdo programático, diretrizes, ações e políticas prioritárias). Governabilidade depende das condições que o governante detém e o que afinal ele pode controlar e não controlar. Um nível baixo de governabilidade dificulta a execução de qualquer projeto de governo, daí o ditame, "nas democracias, ganhar eleições é mais fácil do que governar com eficácia". Governar enfrentando problemas sociais pode ser mais difícil que apenas controlar os problemas. Governar sistemas sociais crescentemente complexos é o desafio mais dramático dos dias de hoje (MULLER, 1998). ${ }^{7}$

No Brasil dos anos de 1990 e em vários países do Mundo, os dados indicavam que não se poderia ignorar as escalas local, nacional e global. Talvez por isso, tenha se difundido a frase emblemática que deu origem ao termo "glocal", agir localmente e pensar globalmente.

De fato, não obstante uma espécie de polarização em torno da importância dos blocos regionais, a exemplo do Mercosul, a idéia da ação política e econômica que integrem vários espaços, sob várias escalas simultaneamente (âmbito trans-escalar) ganha, rapidamente, expressão prática e ressonância teórica. Talvez por isso, e em face da omissão e impotência do Estado como gestor e investidor, tenha emergido com tanto vigor nos anos de 1990, a chamada "guerra dos lugares". Os surtos emancipacionistas ${ }^{8}$ e a guerra fiscal, não obstante vários aspectos pouco nobres que permeiam a questão (clientelismo e oportunismo político, corrupção, etc.), soam também como uma espécie de corrida de obstáculos onde o fim parece ser o ganho de vantagens econômicas para espaços territoriais que perdiam identidade e visibilidade, diante de uma suposta marcha avassaladora da Globalização. Entretanto, tais mudanças, na verdade, se dirigiam também à perspectiva, pouco realista, de se auferir ganhos econômicos em brechas que a reestruturação produtiva mundial abria, sem a intermediação da instância nacional. Quem sabe não se poderia instaurar um processo produtivo "local" e se inserir diretamente em circuitos comerciais globais, sem a mediação de esferas intranacionais?

\footnotetext{
7 Talvez, após o governo Fernando Henrique Cardoso e a emergência do governo Lula, o país descubra que a construção de consensos possíveis, em ambientes de perdas suportáveis a todos, seja a melhor forma de administrar em situações de conflito, se a governabilidade e a capacidade técnica das equipes forem suficientemente consistentes e as prioridades de políticas de governo bem nítidas (como no programa Fome Zero).

${ }^{8}$ No âmbito municipal, a fragmentação territorial experimentou diversos momentos históricos, geralmente associados a fatores diversos de natureza econômica, política, legislativa e financeira. Alguns surtos emancipacionistas foram bastante nítidos como os de 1995/96, 1992, 1962, 1946, entre outro. A fragmentação municipal contemporânea raramente traz benefícios explícitos aos estados e União. Os municípios sobrevivem a custa de repasses estaduais e federais e, sob a lei de responsabilidade fiscal muitos estão juridicamente inviáveis. A hipótese de uma gestão supramunicipal inovada, baseada em construção de consensos de gestão democrática e ganhos de recursos financeiros e materiais poderia racionalizar o planejamento espacial, favorecendo a produção de informações, diminuindo a pulverização de esforços, etc
}

Cadernos do Leste

Artigos Cientificos

Belo Horizonte, Edição Especial, 2000 a 2008 
Algumas evidências contemporâneas autorizavam os agentes a pensarem assim. $\mathrm{O}$ estímulo à competição que a nova economia mundial veiculava e os fluxos planetários de informação em rede traziam possibilidades e indagações. Os novos arranjos espaciais poderiam estar conferindo vantagens comparativas consistentes e maior capacidade competitiva de certos lugares. Isso habilitaria tais lugares a se integrar em "vantagem" às novas contingências do processo de produção?

De toda forma, convém considerar que as mudanças em curso não estão linearmente predeterminadas pela globalização técnica, pelo capital financeiro internacional, ou pela ecologia. Redefinem-se os espaços, mas tudo isso depende de "diferentes condições regionais em potencial de recursos, em iniciativa política, no modo de controlar a informação que, por sua vez, depende da estrutura econômica e social” (BECKER, 1997).

Por esse prisma, as regiões não só não foram anuladas, mas ressurgem como protagonistas importantes na atualidade. Condicionam o modo como os vetores de transformação disseminam efeitos que se propagam no espaço nacional. Teoricamente, a corrente 'evolucionista-institucionalista' observa com propriedade, que ao se pensar regionalmente deve-se procurar endogeinizar as fontes do crescimento econômico, reconhecendo os fatores multiplicadores capazes de gerar economias externas, a possibilidade de se auferir rendimentos estáveis e suficientemente crescentes, e os limites impostos pelo padrão de utilização e consumos de recursos não renováveis. Tudo isso deve ser balisado pelo reconhecimento da história, como responsável pelas condições iniciais do desenvolvimento, da sinergia e força de pequenas e médias empresas locais, das condições ambientais e da presença das articulações local e nacional num sistema aberto cooperativo, de modo a evitar que o bem estar de uma região resulte em mal estar de outras regiões (KRUGMAN, BECATTINI, etc).

Novos investimentos teóricos revigoram a dimensão regional nos últimos anos. A “endogeneização das estratégias de desenvolvimento regional e local” apoia-se em novas contribuições teóricas, da mesma forma que a dimensão técnica não esgota nem elimina a necessidade de resolver novos problemas que a perspectiva do exercício de formas de gestão democrática solidária impõem. Alguns desses problemas, que eram típicos de grandes áreas urbanas saturadas demográfica e economicamente, passam a ganhar visibilidade em espaços geográficos mediterrâneos, ainda de baixa densidade, onde o crescimento e desenvolvimento impõem inéditos desafios à gestão e planejamento.

Cadernos do Leste

Artigos Cientificos

Belo Horizonte, Edição Especial, 2000 a 2008 
No Brasil dos últimos 30 anos isso vem se tornando uma realidade nos processos inéditos de desconcentração econômica e demográfica. Processos cuja origem remonta aos investimentos e à atuação programática do Estado nos anos de 1970, mas que ganhou novas características nos anos de 1980 e 1990, por força da ação "espontânea" de diversos atores. Assim, tanto firmas industriais procuravam alternativas locacionais fora do núcleo paulista hiperconcentrado, como pessoas e famílias tentavam a sorte no grande interior do país. Como resultante, surge, ao final do século, um Brasil mais integrado, amplamente urbanizado em seu interior, mas com níveis desigualdades regionais e sociais inalterados.

Nesse quadro, tendo em vista algumas manifestações que se descortinam no Brasil e no Mundo, como se situaria a problemática urbano-ambiental em sociedades crescentemente urbanizadas, mas profundamente impactadas por atividades consumidoras de espaço localizadas nas grandes extensões territoriais fora das cidades? Ademais, quais articulações se fazem notar nestes diferentes espaços que prenunciam formas de gestão em que o planejamento internalize a dimensão transescalar de modo mais eficiente?

\section{7- BREVES NOTAS SOBRE O DESENVOLVIMENTO URBANO SUSTENTÁVEL}

De fato, novas questões surgem, suscitando múltiplas respostas e consensos difíceis. Uma delas diz respeito à dificuldade de se definir desenvolvimento ambientalmente sustentável, particularmente em contextos urbanos. Como discernir desenvolvimento urbano sustentável? Mera estratégia de marketing ou uma nova utopia que teime em privilegiar a equidade?

Talvez conviesse considerar que há níveis de conflitos teóricos de superação não muito simples. Conflitos entre, por exemplo, as abordagens ambientais e a urbanística estrito senso, entre propostas teóricas de planejamento e a intervenção propriamente dita. In extremis, argui-se sobre a capacidade de a sustentabilidade urbana no capitalismo tornar possível o surgimento de uma nova ética, em bases menos excludentes - mais democráticas e solidárias - como observa, por exemplo, a ecologia política. De toda forma, é inegável que se ampliou o alcance do pensamento ambiental, rumo a uma espécie de sócio ecologia apoiada na diversidade e na democracia. 
Mas afinal, quais são as ações, ou os exemplos relativamente exitosos, que se poderiam registrar, nesse curto espaço de tempo (últimos 30 anos) que demarca o período em que a problemática ambiental procura redesenhar a questão territorial?

Alguns exemplos de desenvolvimento urbano sustentável vêm sendo mencionados nos últimos 15 anos. O primeiro refere-se à proposta europeia das chamadas cidades compactas. A ideia é que a compactação urbana facilita os controles da poluição, otimiza o consumo de energia e a própria forma urbana expõe arranjos espaciais que contém o espraiamento territorial (indesejável), favorecendo o adensamento, o que introduz eficácia na oferta de transporte coletivo, e serviços públicos de qualidade em saneamento e equipamentos de saúde. $\mathrm{O}$ incentivo ao uso misto soaria como antídoto às especializações comerciais, de serviço ou na forma de cidades-dormitórios, altamente dependentes do automóvel. A conexão entre transportes, energia e um desenho urbano que impõe barreiras ao consumo de espaço geográfico escasso torna-se o meio de alcançar sustentabilidade. A proposta de cidades compactas de alta densidade procura mostrar-se ambientalmente mais sustentáveis, redutoras de custos e promotoras de maior qualidade de vida, em assentamento urbano inovado e rico em diversidade em termos de lazer e cultura.

Contudo, em momento em que vários países experimentam a dispersão da urbanização e a desconcentração espacial da população, tais propostas são viáveis? Mesmo na Europa, onde a restrição espacial é notória, a França suspendeu, há poucos anos, a construção de conjuntos habitacionais conceitualmente apoiados nas ideias da urbanização compacta. ${ }^{9}$

Um segundo exemplo diz respeito às cidades sustentáveis da Califórnia. Em torno da Baia de São Francisco diversas instituições e ONGs articularam-se em torno da defesa e manutenção de uma região metropolitana sustentável (grifo nosso). Com isso firmou-se um acordo normativo envolvendo diretrizes de governo voltadas: ao enfrentamento do excessivo predomínio do automóvel; à proteção da biodiversidade e do patrimônio paisagístico; ao combate de bolsões centrais de pobreza; e à defesa de áreas agrícolas como "hábitat" de animais. A sustentabilidade, enfim, apoiava-se em ações voltadas:

\footnotetext{
9 No entanto, dadas as restrições associadas a escassez de combustíveis fósseis e altas irreversíveis de preços de derivados do petróleo nos próximos 15 anos, além de várias outras questões recorrentes relativas aos custos que as distâncias casa-trabalho impõem a todos, torna-se pertinente pensar em formas mais eficientes de assentamentos urbanos que levem em conta a imperiosa necessidade de poupar e diversificar as fontes de energia, eliminando o desperdício e estruturando ambientes mais saudáveis e sustentáveis no longo prazo, mesmo em países de grande extensão territorial como o Brasil.
} 
i) à escolha de opções habitacionais que combinem redução de custos e disponibilidade de áreas verdes, e que estabeleçam coerência entre os tamanhos e solução dos projetos das edificações com o padrão demográfico atual (no qual a população está envelhecida e as famílias são, necessariamente, menores). A prioridade deveria se concentrar nas questões do bairro e vizinhança, emprego e lazer, transporte e interação social;

ii) ao estimulo do sentimento de pertencimento, ao ideal de comunidade e responsabilidade. Nesse ideário, privilegia-se a densificação urbana, em contraste com o ideal dos 'suburbs' (responsáveis pelo alongamento horizontal das cidades). Defende-se a ideia de lugar, espaços públicos, serviços, segurança e menores deslocamentos. $\mathrm{Na}$ escala urbano-regional a ênfase recai sobre o patrimônio histórico e paisagístico, sobre a multiplicidade de usos (residencial e industrial, por exemplo), e sobre a revitalização dos centros decadentes. No nível mais regional a preocupação ambiental mostrou-se mais definitiva e incluía a proteção da baía, do estuário e dos mananciais, a preservação do cinturão natural (suporte a agricultura local), a interação entre espaços verdes livres, o incentivo a todas as formas de conservação e reciclagem (energia, terra e água). A idéia de capacidade de suporte e riscos ambientais percorre todos os casos (COSTA, 2000);

iii) à proteção a natureza e restauração de áreas não construídas;

iv) à justiça social econômica e ambiental;

v) ao respeito à história e singularidade culturais.

\section{8- CONSIDERAÇÕES FINAIS}

Nas últimas décadas, a discussão sobre a oportunidade e adequação da gestão local e regional ganhou destaque, desdobrou-se em várias experiências e reuniu adeptos e críticos de diferentes formações teóricas. A pergunta sobre as vantagens, limites e impossibilidades da ação pública local, particularmente nas áreas urbanas, foi, sem dúvida um dos principais pontos da agenda internacional de debates nos últimos 15 anos, cujos efeitos se desdobram até os dias de hoje. 
Parte das questões em pauta envolve diferentes escalas espaciais, o que por si só introduz complexidade à análise em face de sua dimensão interdisciplinar e transtemporal. Os espaços territoriais estão carregados de história e cultura, o que lhes confere diferenciais de identidade e durabilidade regionais, e isso pode ser encontrado, mais ou menos intensamente, em várias das Unidades da Federação do Brasil. Tais atributos certamente ampliaram a reverberação das práticas governamentais na chamada "guerra fiscal" dos anos de 1990 e ainda podem produzir desdobramentos políticos capazes de por a prova formas de regulamentação federal ainda excessivamente centralizadas.

Uma questão escalar que vem suscitando discussões e, tão cedo, não sai da agenda de debates, diz respeito à obsolescência da definição de áreas urbanas no Brasil, uma vez que o IBGE adota como urbano (sedes municipais e vilas), por força de lei Federal de 1938, o que os municípios estabelecem em seus perímetros "urbanos". O "rural", por exclusão, é o restante.

Cidade e campo, urbano e rural são categorias de análise ainda centrais nos estudos regionais e na reflexão geográfica. É evidente que essa centralidade se atualiza em função dos novos significados que o Habitat e a própria relação Homem-Natureza vêm forjando nos últimos anos. Adicionalmente, no Brasil emerge um novo rural, bastante distante do agro rural do passado, onde antigos conceitos e definições de urbano e rural não mais se aplicam. Certamente, problemas relacionados à alocação de recursos para o desenvolvimento irão se deparar com esse anacronia conceitual brasileira, o que acarreta dificuldades crescentes em termos de gestão territorial regional. É evidente que a gestão transescalar não suprime a necessidade de definição clara sobre os espaços territoriais, sobretudo quando determinados investimentos em um município podem produzir impactos em outros municípios vizinhos ou à jusante de bacias hidrográficas de primeira ordem.

Por outro lado, permanecem sem solução uma série de questões de fundo econômico e social que dialogam diretamente com os limites e possibilidades de utilização eficaz dos espaços territoriais, dadas as restrições e fragilidade que diferentes ambientes naturais e tipos de assentamentos humanos internalizam.

Se é verdade que as pressões populacionais sobre os recursos diminuíram e tendem a diminuir no futuro, é também verdade que durante pelo menos por mais de uma década os contingentes de adultos não irão diminuir (herança de uma época de alta natalidade). Com isso as pressões sobre o mercado de trabalho continuarão aumentando, em momento Cadernos do Leste 
de escassez de empregos formais, de restrições financeiras do Estado e de desesperança. Essa última, uma espécie de efeito perverso da exclusão, empobrecimento e aumento das desigualdades sociais.

As respostas que a economia e os governos podem produzir são certamente inelásticas, mas ainda assim, do ponto de vista regional, devem incorporar os ganhos que a convergência de ações estratégicas é capaz de maximizar. Nesse sentido, atividades econômicas como a agricultura e indústria continuam sendo chaves na geração de riqueza e renda, formação de capital humano e mitigação de pobreza.

Assim, parafraseando Ohmae e outros economistas, a atenção para com a política industrial continua sendo importante, em decorrência dos seus efeitos multiplicadores, inclusive na redução de desigualdades regionais e sociais. A geração de empregos diretos, mas principalmente de indiretos, instaura o ciclo de formação de mão-de-obra e consumidores individuais, condição de sustentabilidade para a atividade econômica, no lato senso. A produção industrial, entretanto, não se realiza sem investimentos, seja de origem pública ou privada. Os investimentos devem ser priorizados para a geração de novas tecnologias, o que pressupõe planejamento e expansão do nível de disseminação de informações e novas práticas de gestão. Gestão que regulamenta, antecipa problemas e soluções, promove agendas inclusivas, interage com o patrimônio ambiental e cultural, aperfeiçoa, enfim, os mecanismos da democracia e do Estado de Direito. 


\section{BIBLIOGRAFIA}

CASTRO, Iná C. Solidariedade territorial e representação; novas questões para o pacto federativo nacional. Rio de Janeiro. Território. LAGET/UFRJ. 1997.

BECKER, Berta. Tendências de transformação do território no Brail. Vetores e Circuitos. Rio de Janeiro. Território. LAGET/UFRJ. 1997.

MULLER, G. O macroeixo São Paulo-Buenos Aires e a gestão territorializada de governos subnacionais. In: CASTRO, Iná E, MIRANDA, M., EGLER, C.A.G. (org.). Redescobrindo o Brasil 500 anos depois. Rio de Janeiro. Bertrand Brasil. 1998.

COSTA, R.H. \& GOMES, P.C.C.. "O espaço na modernidade”. In: TERRA LIVRE; O espaço em questão. AGPl/Marco Zero, São Paulo, 1988, 05:47-67.

COSTA, H.S.M. Desenvolvimento urbano sustentável: uma contradição em termos? In: REVISTA BRASILEIRA DE ESTUDOS URBANOS E REGIONAIS. ANPUR. Recife. 2000.

COMPANS. R. Limites da ação pública local. In: REVISTA BRASILEIRA DE ESTUDOS URBANOS E REGIONAIS. ANPUR. Recife. 2000.

MATOS, R.E.S. Aglomerações urbanas, rede de cidades e desconcentração demográfica no Brasil. XII Encontro Nacional de Estudos Populacionais. Caxambu, out., ABEP, 2000.

MATOS, R.E.S. O Brasil dividido e a rede urbana fracionada. CADERNO DO LESTE. Belo Horizonte, jan., 2003.

MATOS, Ralfo e BRAGA, Fernando G. Rede urbana e redistribuição espacial da população brasileira. Anais do XIII Encontro Nacional de Estudos Populacionais, nov. de 2002.

GUIMARÃES, F. "Divisão regional do Brasil". In: REVISTA BRASILEIRA DE GEOGRAFIA, Rio de Janeiro, 1941, n. 37. 